\title{
Economic Estimation of Nursing Services under the Diagnostic Procedure Combination/Per-Diem Payment System
}

Tomoya Akiyama ${ }^{1}$, Naomi Akiyama $^{2 *}$, Kenshi Hayashida ${ }^{3}$ and Hiroshi Tamura ${ }^{1}$

${ }^{1}$ Kyoto University Hospital, Kyoto, Japan

${ }^{2}$ Department of Nursing, School of Health Sciences, Bukkyo University, Kyoto, Japan

${ }^{3}$ University of Occupational and Environmental Health, Kokura, Japan

\begin{abstract}
Aim: The purpose of this study was to determine whether the amount of nursing services estimated under the classification of Nursing Need Degree is adequately evaluated for each Diagnostic Procedure Combination (DPC) reimbursement.
\end{abstract}

Methods: A longitudinal cohort study design was employed to examine all 28,757 hospitalizations, except for those due to tuberculosis, in Hospital A in Japan between July 2008 and March 2010. We excluded the following patients from analysis: patients who were not applicable to the DPC system; patients who were hospitalized beyond the specified DPC period; and patients who were applicable to the specified hospital fee. We collected data from the administration system of medical business and Nursing Need Degree (NND). We calculated the mean of the hospital fee portion (i.e., fees for room and nursing services) per total number of nurses required and created a list of per-nurseday unit price for each DPC group, only if the number of patients included in the identical DPC group exceeded 20. We described about the number of assigned DPC codes, in such a way as to distribution of percent difference from the mean of hospital fee portion/total necessary number of nurses for each DPC group. In addition, we focused on the difference from the mean by $30 \%$.

Results: A significant correlation was found between the hospital fee portion and total number of nurses required under the DPC system. However, the distribution of percent differences among the mean of the hospital fee portion per total number of nurses required revealed that 39 of 179 DPC code groups were either underestimated or overestimated. The underestimated group included a number of obstetrics- and gynecology-related diseases, whereas the overestimated group included many non-surgical, cancer-related diseases.

Conclusions: Our results significantly contribute to the identification of DPC codes that do not adequately reflect nursing services required under the present DPC payment system.

Keywords: Health care costs; Payment system; Nursing services; Personnel staffing and scheduling; Nursing administration research

Abbreviations: DPC: Diagnostic Procedure Combination; OECD: Organization for Economic Co-operation and Development; PPS: Prospective Payment System; DRGs: Diagnostic Related Groups; NND: Nursing Need Degree

\section{Introduction}

Many developed countries share growing concerns over care methods and increased health care expenditures due to improved life expectancy among the elderly. Health care costs in Japan are lower compared to the United States and other countries according to the 2008 Organization for Economic Co-operation and Development (OECD) report [1].

In the United States, a prospective payment system (PPS), such as Medicare's system of reimbursement based on a set of predetermined in-patient care costs, is employed to establish separate payments according to Diagnostic Related Groups (DRGs) [2]. The DRG system is a patient classification scheme that provides a means to relate the type of patients treated by a hospital to the costs incurred in the hospital [3]. In 2003, a new reimbursement system known as the Diagnostic Procedure Combination (DPC) was introduced in acute-care hospitals [4]. The DPC is not a case payment system, but is a per diem payment system based on patient classifications. The cost depends on the length of hospital stay, and if hospitalization is prolonged beyond the specified period, the DPC-based payment will no longer be applied; instead, a traditional fee-for-service payment system will be adopted [3].

In the 1980s, nursing professionals examined the effect of DRGs and PPS on nursing costs or nursing services [5-8]. Previous studies suggest that DRGs properly reflect nursing services involved in the provision of nursing care for patients classified under the DRG system [2,7-9]. Meanwhile, a comprehensive nursing index was developed at Johns Hopkins University, introducing the first nursing patient classification system [10]. Many case-mix studies, such as the measurement of severity of patients' illnesses, were conducted in relation to nursing care $[8,10]$.

In Japan, a new nursing patient classification system called the "Nursing Need Degree (NND)," which is categorized by the need for nursing care services, was introduced in 2000 in order to estimate nursing manpower for each patient day. Since 2006, it has been recommended that hospitals measure the NND daily for each patient and allocate nurses accordingly under the regulations of the hospital fee reimbursement system. Japanese nurses can measure the total amount of nursing services according to the universal scale of NND.

Siferd and Benton [8] reported that, traditionally, the costs of nursing services have been included in the hospital room fees. The same can be said for the costs of nursing services in Japan. Since the costs of

*Corresponding author: Naomi Akiyama, Department of Nursing, School of Health Sciences, Bukkyo University, 2-7 Nishinokyo Boo-tyo, Nakagyo-ku, Kyoto, Japan, 604-8415, Tel: +81-75-491-2141; Fax: +81-75-366-5757; E-mail: n-akiyama@bukkyo-u.ac.jp

Received January 25, 2013; Accepted April 30, 2013; Published May 06, 2013

Citation: Akiyama T, Akiyama N, Hayashida K, Tamura H (2013) Economic Estimation of Nursing Services under the Diagnostic Procedure Combination/PerDiem Payment System. J Nurs Care S5: 008. doi: 10.4172/2167-1168.S5-008

Copyright: ( 2013 Akiyama T, et al. This is an open-access article distributed under the terms of the Creative Commons Attribution License, which permits unrestricted use, distribution, and reproduction in any medium, provided the original author and source are credited. 
in-patient nursing services comprise the hospital fee portion (i.e., fees for room and nursing services) under the DPC system, it is not clear whether nurses' work would be subjected to adequate evaluation. To provide high quality nursing care for patients in Japan, it is important to determine how properly nursing services are estimated under the DPC system; however, few reports exist on the relationship between the DPC and NND in Japan. Accordingly, this study aimed to determine whether the amount of nursing services estimated under the classification of NND is adequately evaluated for each DPC reimbursement.

\section{Methods}

\section{Patients}

A longitudinal design was employed to examine all 28,757 hospitalizations, except for those due to tuberculosis, in Hospital A between July 2008 and March 2010. Hospital A is an acute-care university hospital with more than 1,000 beds. We excluded the following patients from analysis: patients who were not applicable to the DPC system; patients who were hospitalized beyond the specified DPC period; and patients who were applicable to the specified hospital fee (e.g., intensive care unit fee, hospital fee for the elderly aged 75 years or over) if only for a day through his/her hospitalization.

\section{Data collection}

We collected data from the administration system of medical business and NND. Medical business data included patient number, sex, date of admission and discharge, age at discharge, DPC code at discharge, length of hospital stay, gross income under the DPC payment system, gross income under the fee-for-service payment system, the sum of hospital fee elements (room and board, nursing services, and laboratory costs) under the fee-for-service payment system, application to the specified hospital fee, death before/after discharge, and whether or not hospitalization was prolonged beyond the specified DPC period. NND data included patient number, daily NND score of severity and nursing care needs assessment indicator for general ward, daily NND score of severity and nursing care needs criteria, and daily patient classification levels. The NND consists of two scores: score A, which measures the level of medical care and the number or presence/absence of monitoring and treatment consisting of 15 items (e.g., blood pressure taking, electrocardiogram monitoring, respiratory care), and score $\mathrm{B}$, which measures the patient condition, including 13 items (e.g., rolling-over, transfer, dietary intake), those items should be answered selecting an appropriate one from two or three choices (e.g., without assistance, some assistance, full assistance) $[11,12]$. Each of those choices is assigned a score from 0 to 1 or 2 . Score A and B are calculated respectively by adding together. The NND for each patient is determined by the combination of score $\mathrm{A}$ and $\mathrm{B}$.

\section{Assumed hospital fee portion under the DPC payment system}

Under the DPC payment system, reimbursement of medical fees is calculated based on the sum of the prospective payment and fee-forservice payment portions. The prospective payment portion consists of hospital fee elements, which include a portion of fees associated with medical care (i.e., examination, diagnostic imaging, medication/ injection/treatment, medication during rehabilitation, mental treatment). The fee-for-service portion corresponds to all other fees not included in the prospective payment portion.

The assumed hospital fee portion under the DPC payment system was calculated by subtracting the difference between the sum of hospital fee elements and the gross income under the fee-for-service payment system from the gross income under the DPC payment system.

\section{Calculation of the total number of nurses required}

Sovie et al. [7] assigned nursing care hours to categories of nursing acuity in a detailed time study of nursing hours spent for patient care and unit related activities. During the process of developing NND, the government investigation team conducted extensive time studies on nursing care hours [12]. In the present study, we estimated the total number of nurses required for each patient hospitalization based on his/her daily NND data from the date of admission to discharge.

\section{Analysis}

We used one-way ANOVA to analyze data and the chi-square test to compare characteristics between surgical, non-surgical, and other cases. In addition, the Tukey-Kramer test was performed for multiple comparisons between groups. We used generalized liner modeling to investigate the relationship between the hospital fee portion under the DPC system and the total number of nurses required.

We calculated the mean of the hospital fee portion per total number of nurses required for each patient hospitalization, and created a list of per-nurse-day unit price for each DPC group, only if the number of patients included in the identical DPC group exceeded 20. We described the number of assigned DPC codes in a way that distribution of percent difference from the mean of hospital fee portion per total number of nurses required for each DPC group. In addition, we focused on the difference from the mean by $30 \%$.

All statistical analyses were performed using JMP Statistical Software Version 9.0. $\mathrm{p}<0.05$ was considered statistically significant. This study was approved by the Ethics Committee of the Kyoto University.

\section{Results}

\section{Patient characteristics and costs}

The extracted dataset included 28,757 observations between July 2008 and March 2010. Of these, 476 observations could not be connected to either medical business data or NND data; 7,247 observations were excluded for not adopting the DPC system $(n=2,307)$, having a prolonged length of hospital stay beyond the specified period of DPC $(n=3,870)$, or adopting the specified hospital fee $(n=1,651)$. Consequently, we analyzed 21,007 observations.

Table 1 shows patient characteristics, including income. The mean age was 56 years, and $52 \%$ of patents were male. The mean length of hospital stay was 13 days, and the sum of hospital fee elements under the DPC payment system (A) was $\$ 3626$ and the total number of nurses required (B) was 5 person.

Patient characteristics were evaluated based on three classifications: surgical, non-surgical, and "others." Patients in the surgical group were older and had a longer length of hospital stay than the "others" group (Tukey-Kramer test, $\mathrm{p}<0.001$ ).

The mean of the sum of hospital fee elements under the DPC payment system (A) and the total number of nurses required (B) were higher in the surgical group than the "others" group (Tukey-Kramer test, $\mathrm{p}<0.001)$. The non-surgical group had the highest mean $(\mathrm{A}) /(\mathrm{B})$ (\$953/nurse-day), followed by the "others" group ( $\$ 831 /$ nurse-day) and the surgical group ( $\$ 776 /$ nurse-day) (Tukey-Kramer test, $\mathrm{p}<0.001$ ).

\section{DPC codes}

We divided 582 groups according to the first six digits of the DPC code (diagnosis) and the $9-10^{\text {th }}$ digits (surgical/non-surgical/others). Small groups consisting of less than 20 observations demonstrated the 
Citation: Akiyama T, Akiyama N, Hayashida K, Tamura H (2013) Economic Estimation of Nursing Services under the Diagnostic Procedure Combination/Per-Diem Payment System. J Nurs Care S5: 008. doi: 10.4172/2167-1168.S5-008

Page 3 of 5

\begin{tabular}{|c|c|c|c|c|c|c|}
\hline & & All & Non-surgical & Surgical & Others & \multirow{2}{*}{$\mathrm{p}$-value } \\
\hline & & $n=21,828$ & $n=10121$ & $\mathrm{n}=9812$ & $\mathrm{n}=1895$ & \\
\hline Age & mean $\pm \mathrm{SD}$ & $55.9 \pm 21.7$ & $54.1 \pm 22.4$ & $58.4 \pm 20.2$ & $52.6 \pm 23.5$ & $* * a)$ \\
\hline Sex (male) & $\mathrm{n}(\%)$ & $10846(51.6)$ & $4978(51.5)$ & $4949(52.0)$ & $919(50.4)$ & n.s.b) \\
\hline Length of hospital stay (day) & mean \pm SD & $12.8 \pm 12.1$ & $10.6 \pm 11.0$ & $14.9 \pm 13.1$ & $13.4 \pm 10.7$ & **a) \\
\hline Gross income, prospective & mean \pm SD & $9160.0 \pm 9623.6$ & $5845.9 \pm 5631.3$ & $12865.5 \pm 11581.8$ & $7376.4 \pm 8097.0$ & $* *$ a) \\
\hline Gross income, fee-for-service & mean $\pm \mathrm{SD}$ & $8762.2 \pm 9363.8$ & $5284.9 \pm 5004.7$ & $12617.7 \pm 11388.5$ & $7060.7 \pm 7464.7$ & $* *$ a) \\
\hline Sum of hospital fee elements under the DPC system; $(A)(\$)$ & mean $\pm \mathrm{SD}$ & $3626.1 \pm 3491.2$ & $3219.5 \pm 3305.9$ & $4017.2 \pm 3640.1$ & $3739.0 \pm 3412.9$ & $* *$ a) \\
\hline Total number of nurses required ; (B) (person) & mean \pm SD & $5.3 \pm 7.0$ & $4.1 \pm 5.5$ & $6.5 \pm 8.0$ & $5.4 \pm 7.0$ & $* * *$ a) \\
\hline$A / B(\$)$ & mean \pm SD & $862.2 \pm 506.6$ & $953.4 \pm 615.3$ & $775.7 \pm 373.9$ & $831.3 \pm 369.7$ & **ta) \\
\hline
\end{tabular}

a) One-way ANOVA, b) chi-square test

Table 1: Patient characteristics.

\begin{tabular}{|c|c|c|}
\hline Percent difference & Range & Number of assigned DPC codes \\
\hline$>30 \%$ more & $X<\$ 577.9$ & 21 \\
\hline $25-30 \%$ less & $\$ 577.9 \leq X<\$ 619.1$ \\
\hline $20-25 \%$ less & $\$ 619.1 \leq X<\$ 660.4$ & 8 \\
\hline $15-20 \%$ less & $\$ 660.4 \leq X<\$ 701.7$ & 11 \\
\hline $10-15 \%$ less & $\$ 701.7 \leq X<\$ 743.0$ & 11 \\
\hline $5-10 \%$ less & $\$ 743.0 \leq X<\$ 784.2$ & 15 \\
\hline $0-5 \%$ less & $\$ 784.2 \leq X<\$ 825.5$ & 13 \\
\hline No difference & $\$ 825.5$ & 0 \\
\hline $0-5 \%$ more & $\$ 825.5<X \leq \$ 866.8$ & 24 \\
\hline $5-10 \%$ more & $\$ 866.8<X \leq \$ 908.1$ & 14 \\
\hline $10-15 \%$ more & $\$ 908.1<X \leq \$ 949.3$ \\
\hline $15-20 \%$ more & $\$ 949.3<X \leq \$ 990.6$ \\
\hline $20-25 \%$ more & $\$ 990.6<X \leq \$ 1031.9$ \\
\hline $25-30 \%$ more & $\$ 1031.9<X \leq \$ 1073.2$ & 12 \\
\hline$>30 \%$ more & $X>\$ 1073.2$ & 10 \\
\hline
\end{tabular}

$X:$ The mean of the hospital fee portion per total number of nurses required by DPC.

Table 2: Distribution of percent differences among the hospital fee portion per total number of nurses required for each DPC group.

large dispersion of the sum of hospital fee elements under the DPC payment system per total number of nurses required (Min: \$-11; Max: $\$ 2774$ ) compared to that of larger groups consisting of 20 observations or more (Min: \$190; Max: \$1647) (data not shown in tables). We analyzed 179 groups consisting of over 20 observations.

We found strong positive relationship between the sum of hospital fee elements under the DPC payment system and the total number of nurses required (GLM, Residual Deviance: 2.32e+10, AIC: 350314.0, $\mathrm{p}<0.001)$.

\section{Distribution of percent differences among the mean of the hospital fee portion per total number of nurses required by DPC codes}

Table 2 shows the distribution of percent differences among the mean of the hospital fee portion under the DPC payment system per total number of nurses required by DPC codes. The results indicate that approximately 108 of 179 DPC codes show variation within plus or minus $20 \%$ of the mean of the sum of hospital fee elements under the DPC payment system (A)/total number of nurses required (B).

Groups with a (A)/(B) less than $30 \%$ of the mean were assigned 21 of 179 DPC codes. We defined the cluster of these DPC codes as the underestimated group in terms of per-nurse-day unit price under the DPC payment system. On the other hand, groups with a (A)/(B) more than $30 \%$ of the mean were assigned 18 of 179 DPC codes. We defined this cluster as the overestimated group.
Per-nurse-day unit price under the DPC payment system for underestimated and overestimated groups

Table 3 lists the per-nurse-day unit price under the DPC payment system for the 21 DPC code groups classified as underestimated.

The minimum mean (A)/(B) was $\$ 190$ for "Disorders of newborns related to short gestation and low birth weight," followed by $\$ 360$ for "Diabetes in pregnancy," and \$430 for "Malignant neoplasm of renal pelvis." As for diagnosis and treatment, 5 of 21 DPC codes were of the obstetrics and gynecology department, 4 of 21 of the hepato-biliarypancreatic division, and 3 of 21 of the urinology or neurosurgery department. Thirteen of 21 DPC codes were in the surgical group.

Table 4 lists the per-nurse-day unit price under the DPC payment system for the 18 DPC code groups classified as overestimated.

The maximum mean (A)/(B) was $\$ 1650$ for "Malignant neoplasm of ovary," followed by $\$ 1600$ for "Retinal vascular occlusions," and $\$ 1520$ for "Malignant neoplasm of cervix uteri/corpus uteri." As for diagnosis and treatment, 3 of 18 DPC codes were of the ophthalmology department, and 2 of 18 of the obstetrics and gynecology, gastroenterology, or breast surgery department. Fourteen of 18 DPC codes were in the nonsurgical group, and 8 of 18 were related to cancer.

\section{Discussion}

In this study, we aimed to identify an association between the NND and DPC. In the discussion, we will set forth the following 
Citation: Akiyama T, Akiyama N, Hayashida K, Tamura H (2013) Economic Estimation of Nursing Services under the Diagnostic Procedure Combination/Per-Diem Payment System. J Nurs Care S5: 008. doi: 10.4172/2167-1168.S5-008

Page 4 of 5

\begin{tabular}{|c|c|c|c|c|}
\hline DPC codes & $\begin{array}{l}\text { ICD-10 approximated to } \\
\text { DPC code }\end{array}$ & Diagnosis and treatment department & Surgical or not & $\begin{array}{c}(\mathrm{A}) /(\mathrm{B}) \\
\$ \text { per nurse day }\end{array}$ \\
\hline $\begin{array}{l}\text { Disorders of newborn related to short gestation } \\
\text { and low birth weight }\end{array}$ & P07 & Obstetrics and Gynecology, Pediatrics, etc. & Non-surgical & 189.8 \\
\hline Diabetes in pregnancy & O249 & Obstetrics and Gynecology & Others & 364.3 \\
\hline Malignant neoplasm of renal pelvis & C65 & Urinology & Non-surgical & 430.7 \\
\hline $\begin{array}{l}\text { Complete or unspecified spontaneous } \\
\text { abortion without complication }\end{array}$ & $\mathrm{O} 039$ & Obstetrics and Gynecology & Surgical & 452.9 \\
\hline $\begin{array}{l}\text { Other psychoactive substance } \\
\text { related disorders }\end{array}$ & F190 & Emergency or General Medicine & Others & 462.3 \\
\hline $\begin{array}{l}\text { Nontraumatic intracranial hemorrhage, } \\
\text { unspecified }\end{array}$ & 1629 & Cranial Nerve Surgery & Non-surgical & 463.6 \\
\hline Tachycardia, unspecified & R000 & Cardiovascular Internal Medicine & Surgical & 465.1 \\
\hline Calculus of gallbladder without cholecystitis & K802 & Division of Hepato-Biliary-Pancreatic Surgery & Surgical & 504.7 \\
\hline Abnormality of forces of labor, unspecified & O629 & Obstetrics and Gynecology & Surgical & 512.4 \\
\hline Disease of intestine, unspecified & K639 & Urinology & Surgical & 529.7 \\
\hline $\begin{array}{l}\text { Pre-existing hypertension complicating pregnancy, } \\
\text { childbirth, and the puerperium }\end{array}$ & O10 & Obstetrics and Gynecology & Surgical & 534.3 \\
\hline Hydrops of gallbladder & K821 & Division of Hepato-Biliary-Pancreatic Surgery & Surgical & 539.5 \\
\hline Intracranial injury & S06 & Neurosurgery, etc. & Surgical & 543.2 \\
\hline $\begin{array}{l}\text { Intraoperative and postprocedural complications } \\
\text { and disorders of digestive system }\end{array}$ & K91 & $\begin{array}{l}\text { Division of Hepato-Biliary-Pancreatic Surgery, } \\
\text { etc. }\end{array}$ & Non-surgical & 545.5 \\
\hline Hydrocephalus, unspecified & G919 & Neurosurgery & Surgical & 555.7 \\
\hline Other and unspecified atherosclerosiS & 1709 & Cardiovascular Medicine, etc. & Surgical & 560.3 \\
\hline Enlarged prostate & N40 & Urinology, etc. & Surgical & 567.1 \\
\hline Other and unspecified cirrhosis of liver & K746 & $\begin{array}{l}\begin{array}{l}\text { Division of Hepato-Biliary-Pancreatic Surgery, } \\
\text { etc. }\end{array}\end{array}$ & Non-surgical & 567.3 \\
\hline Malignant neoplasm of thyroid gland & $\mathrm{C} 73$ & Radiation Oncology, etc. & Non-surgical & 571.8 \\
\hline Cerebral aneurysm, nonruptured & 1671 & Neurosurgery & Surgical & 574.0 \\
\hline Longitudinal reduction defect of radius & Q714 & $\begin{array}{l}\text { Plastic and Reconstructive Surgery } \\
\text { or Orthopedic Surgery }\end{array}$ & Surgical & 574.1 \\
\hline
\end{tabular}

A: Sum of hospital fee elements B: Total number of nurses required

Table 3: Per-nurse-day unit price under the DPC payment system for the underestimated group.

\begin{tabular}{|c|c|c|c|c|}
\hline DPC codes & $\begin{array}{l}\text { ICD-10 approximated } \\
\text { to DPC code }\end{array}$ & $\begin{array}{c}\text { Diagnosis and treatment } \\
\text { department }\end{array}$ & Surgical or not & $\begin{array}{c}(A) /(B) \\
\$ \text { per nurse day }\end{array}$ \\
\hline Malignant neoplasm of ovary & C56 & Obstetrics and Gynecology & Non-surgical & 1646.7 \\
\hline Retinal vascular occlusions & H34 & Ophthalmology & Non-surgical & 1597.2 \\
\hline Malignant neoplasm of cervix uteri/corpus uteri & C539/C549 & Obstetrics and Gynecology & Non-surgical & 1522.0 \\
\hline Degeneration of macula and posterior pole & H353 & Ophthalmology & Non-surgical & 1409.6 \\
\hline Malignant neoplasm of breast of unspecified site & C509 & Breast Surgery & Non-surgical & 1314.5 \\
\hline Pulmonary heart disease, unspecified & 1270 & Pediatrics & Non-surgical & 1296.8 \\
\hline Neoplasm of uncertain behavior of breast & D486 & Breast Surgery & Surgical & 1275.9 \\
\hline Melanoma in situ, unspecified & D039 & Dermatology, etc. & Non-surgical & 1261.3 \\
\hline Inflammatory polyneuropathy & G61 & Neurology & Others & 1243.5 \\
\hline Malignant neoplasm of esophagus, unspecified & C159 & Gastroenterology, etc. & Non-surgical & 1241.9 \\
\hline Malignant neoplasm of stomach, unspecified & C169 & $\begin{array}{l}\text { Gastroenterology and Hepatology } \\
\text { or Gastroenterological Surgery, etc. }\end{array}$ & Non-surgical & 1241.1 \\
\hline Malignant neoplasm of breast of unspecified site & C509 & Breast Surgery & Surgical & 1155.0 \\
\hline Non-Hodgkin's lymphoma, unspecified & C859 & Hematology and Oncology, etc. & Non-surgical & 1140.6 \\
\hline Spinal stenosis & M48 & Anesthesia, etc. & Non-surgical & 1113.9 \\
\hline Aortic aneurysm of unspecified site Aneurysm of iliac artery & I719/723 & Cardiovascular Surgery & Non-surgical & 1109.2 \\
\hline Atopic dermatitis & L20 & Dermatology & Others & 1101.6 \\
\hline Unspecified glaucoma & $\mathrm{H} 409$ & Ophthalmology & Non-surgical & 1088.0 \\
\hline Malignant neoplasm of prostate & $\mathrm{C} 61$ & Urinology & Non-surgical & 1074.1 \\
\hline
\end{tabular}

A: Sum of hospital fee elements B: Total number of nurses required

Table 4: Per-nurse-day unit price under the DPC payment system for the overestimated group.

two major points based on our findings. First, there was a significant association between the hospital fee portion and total number of nurses required under the DPC system. However, the distribution of percent differences among the mean of the hospital fee portion per total number of nurses required revealed that 39 of 179 DPC codes fall under the underestimated or overestimated evaluation category. Second, the underestimated group included a number of obstetricsand gynecology-related diseases, whereas the overestimated group 
Citation: Akiyama T, Akiyama N, Hayashida K, Tamura H (2013) Economic Estimation of Nursing Services under the Diagnostic Procedure Combination/Per-Diem Payment System. J Nurs Care S5: 008. doi: 10.4172/2167-1168.S5-008

Page 5 of 5

included many non-surgical, cancer-related diseases.

The strong correlation between the hospital fee portion and total number of nurses required under the DPC system suggests that DPC grouping properly reflects nursing services involved in the provision of care for patients classified under each DPC group. The same trend was observed in the United States with the DRG system regarding nursing services [5-8]. However, the range of the hospital fee portion per total number of nurses required for each DPC group was large.

In this study, we focused on both underestimated and overestimated DPC code groups. The underestimated group has two possible causes: first, the total number of nurses required might be overestimated under the classification based on NND; and second, the hospital fee portion might be underestimated in the DPC system. The underestimated group included a number of obstetrics- and gynecology-related diseases, as well as hepato-biliary-pancreatic diseases. Patients with these diseases are often considered incapable of conducting daily activities without extensive assistance; hence, the total number of nurses required might be overestimated.

On the other hand, the overestimated group has two possible causes; first, the total number of nurses required might be underestimated under the classification based on NND, and second, the hospital fee portion might be overestimated in the DPC system. Almost all DPC codes in the overestimated group were of non-surgical or cancerrelated diseases. Furthermore, patients in this group were administered antitumor drugs. Antitumor drug therapy may require nursing services that are not properly evaluated by the NND. A number of studies have suggested that adequate staffing is associated with improved patient outcomes [13-15]. Moreover, high patient-to-nurse ratios more likely lead to low burnout and dissatisfaction $[15,16]$. Future studies are needed to clarify the number of nurses required for antitumor drug therapy under the classification of NND. Furthermore, the fact that the costs of antitumor drugs would be overestimated in the current DPC system should be taken into consideration.

There are several limitations to this study. First, the analyses were performed in only one acute-care hospital; therefore, generalization of the results requires caution, and further investigation involving other acute hospitals is warranted. Second, we excluded small groups consisting of less than 20 observations. Additional studies should be performed with a larger sample size. Despite these limitations, our results significantly contribute to the identification of DPC codes that do not adequately reflect nursing services under the present DPC payment system.

\section{Acknowledgements}

We thank Mr. Hironobu Murano, a staff member of the Department of Business Management in Hospital A, for assistance in data preparation.
This study was supported by a grant from the Kimura Foundation for Nursing Education.

\section{References}

1. Organisation for economic co-operation and development (2011) Stat extracts. OECD health data 2011 http://stats.oecd.org/index. aspx?DataSetCode=HEALTH STAT; accessed December 20, 2012.

2. Cromwell J, Price KF (1988) The sensitivity of DRG weights to variation in nursing intensity. Nurs Econ 6: 18-26.

3. Tatara K, Okamoto E (2009) Health Systems in Transition Japan Health system review European Observatory on Health Systems and Policies http://www.euro who.int/_data/assets/pdf_file/0011/85466/E92927.pdf ; accessed December 20, $201 \overline{2}$.

4. Hayashida K, Imanaka Y, Otsubo T, Kuwabara K, Ishikawa KB, et al. (2009) Development and analysis of a nationwide cost database of acute-care hospitals in Japan. J Eval Clin Pract 15: 626-633.

5. Kirby KK (1986) Issues in nursing resource management: past and present Nurs Econ 4: 305-309.

6. Grimaldi PL, Micheletti JA (1982) DRG reimbursement: RIMs \& the cost of nursing care. Nurs Manage 13: 12-22.

7. Sovie MD, Tarcinale MA, VanPutte AW, Stunden AE (1985) Amalgam of nursing acuity, DRGs and costs. Nurs Manage 16: 22-42.

8. Siferd SP, Benton WC (1992) Workforce staffing and scheduling: Hospital nursing specific models. European Journal of Operational Research 60: 233246.

9. Price KF, Lake ET (1988) ProPAC's assessment of DRGs and nursing intensity. Nurs Econ 6: 10-16.

10. Reitz JA (1985) Toward a comprehensive Nursing Intensity Index: Part II Testing. Nurs Manage 16: 31-42.

11. Halloran EJ, Kiley M (1984) Case mix management. Nurs Manage 15: 39-41, 44-5.

12. Tsutsui T (2008) Applying Nursing Need Degree to nursing management. Iryoto- Bunka-sya Press (in Japanese)

13. Tsutsui T (2003) The second edition nursing need degree- A new evaluation standard of the nursing service. The Japan Nursing Association Press (in Japanese).

14. Lankshear AJ, Sheldon TA, Maynard A (2005) Nurse staffing and healthcare outcomes: a systematic review of the international research evidence. ANS Adv Nurs Sci 28: 163-174.

15. Seago JA, Williamson A, Atwood C (2006) Longitudinal analyses of nurse staffing and patient outcomes: more about failure to rescue. J Nurs Adm 36 $13-21$

16. Aiken LH, Clarke SP, Sloane DM, Sochalski J, Silber JH (2002) Hospital nurse staffing and patient mortality, nurse burnout, and job dissatisfaction. JAMA 288 1987-1993. 